\title{
Nurses' daily life: gender relations from the time spent in hospital ${ }^{1}$
}

\author{
Audrey Vidal Pereira ${ }^{2}$
}

Objective: to analyze the everyday life of nurses through the sexual work division as well as through interdependence relations and the time in hospital. Method: quanti-qualitative study, based on the Time Use Survey and in Norbert Elias's Configuration Theory of Interdependencies. Daily shifts distribution record, directed by 42 participants - with self-confrontation - by interviews which drew dialogues on subjective aspects of the everyday experiences related to use of time, based on a job at a university hospital. The theoretical intake that founded data analysis was based on concepts of conflicts of interest, power struggles, sexual work division and polychronic-monochronic concepts - whether the work environment demands multitasking nurses or not. Results: time records allowed to observe differences between the groups studied, useful to identify conflicts, tensions, power struggles and gender inequalities in interviewees' everyday affairs that do not only affect physical and mental health, but also their way of life. Conclusion: the analytical path pointed out the need for public policies that promote equity in gender relations, keeping at sight the exercise of plural discourses and tolerant stances capable to respect differences between individual and collective time.

Descriptors: Time Management; Workload; Work; Nurses; Nurses, Male.

\footnotetext{
1 Paper extracted from doctoral dissertation "Os tempos e relações de gênero: o cotidiano de enfermeiras e enfermeiros a partir do tempo de trabalho no hospital", presented to Escola Nacional de Saúde Pública, Fundação Oswaldo Cruz, Rio de Janeiro, RJ, Brazil. Supported by Coordenação de Aperfeiçoamento de Pessoal de Nível Superior (CAPES), Brazil, process \# 2518-12-0.

2 PhD, Adjunct Professor, Escola de Enfermagem Aurora de Afonso Costa, Universidade Federal Fluminense, Niterói, RJ, Brazil.
}

Corresponding Author: Audrey Vidal Pereira Universidade Federal Fluminense

Escola de Enfermagem Aurora de Afonso Costa

Rua Dr. Celestino, 74

Centro

CEP: 24020-091, Niterói, RJ, Brasil

E-mail: auviprof@yahoo.com.br
Copyright () 2015 Revista Latino-Americana de Enfermagem This is an Open Access article distributed under the terms of the Creative Commons Attribution Non-Commercial License (CC BY-NC).

This license lets others distribute, remix, tweak, and build upon your work non-commercially, and although their new works must also acknowledge you and be non-commercial, they don't have to license their derivative works on the same terms. 


\section{Introduction}

Based on the sexual work division and the interdependencies present in public/private interface, the everyday life of female and male nurses was the object of research for the doctoral thesis in Public Health, whose elaboration was held through gender relation analysis, from the scope of work, considering the Configuration Theory of Interdependencies ${ }^{(1-2)}$ and the sexual work division categories $^{(3)}$ as well as multitasking concepts $^{(4-5)}$.

Empirically, both aspects of personal life, as well as the professional exercise of the nurses category contributed, over the years, to the reflection as to what extent these workers coexist with multiple job links, and in nocturnal and weekend scales, featuring accelerated routines and overlapping actions between spaces and times of paid work and other daily activities.

During the research - based on the keywords nursing and time - it was possible to point out countless publications related to the recovery of paid work time. The literature that combines the spoken concepts at the time of review - dealt with concepts such as: daily attendance hours, procedures duration, time of nursing consultation, professional performance time and absenteeism. On the other hand, a gap concerning scientific literature in the nursing field was verified, in relation to the time related to unpaid activities, namely, housework, leisure activities and free time.

Most studies about time associated with professional practice probably relates to the use of the term nursing, as referring to a profession. However, the literature review helped ratifying the importance of investigating the relationship between times and spaces, with emphasis on gender issues in the lives of these workers, extrapolating the context of paid work.

In this way, it is necessary to share some questions about the relationship between the profession of female and male nurses and the sexual work division, based on the use of time: to what extent do uninterrupted timetables in the hospital work interfere in the everyday use of time of these professionals? Despite having suffered influence of a female training and a later and progressive insertion concerning positions in hospital management, have female nurses managed to occupy their time so that they actually modify traditional gender relations in private life? Despite approaching the spaces of power positions in the hospital, graduating and working in a profession historically taken as feminine, are male nurses occupying time in the private sphere, so that they contribute to minimize gender asymmetries?

Considering the respective inquiries, the focus of this essay aimed to analyze the everyday life of female and male nurses through sexual work division and interdependence relations, based on the time in the hospital. For this, it was necessary to describe the everyday time use of female and male nurses over the course of a week; identify the experiences of simultaneous actions in the uses of time; identify conflicts and power struggles in the experiments of time uses; and reflect on relationships of tensions and conflicts and interference in health conditions.

\section{Methods}

This is a study based on the Time Use Survey ${ }^{(6-18)}$ and on the Configuration of Interdependencies Theory ${ }^{(1-2)}$. It was based on the proposed quantiqualitative methods triangulation, yielding a dynamic of investigation that integrates objective analyses, understanding of relationships and differentiated vision of the fieldwork participants. Choosing the triangulation of information relates to the character of the object, since the social phenomena related to the uses of time cause qualitative and quantitative analysis, so as to make clear the objective and subjective aspects of daily work hours ${ }^{(6-8)}$. Thus, to correlate daily work-hour ratings and statements to subjective aspects ensures the possibility to look at time itself quantified and reflect on daily experiences.

The field research was carried out in a hospital located in an urban metropolitan center in the State of Rio de Janeiro, during January and February of 2012. The choice of this location came about due to the possibilities of observation of overlapping action experiences and constrained uses of time through the complexities and specificities that occur in major cities, especially the temporal organization of work, as it includes sectors that 
adopt a modus operandi to meet the need for maintenance of activities, uninterruptedly, 24 hours a day, seven days of the week.

Data collection was carried out in two successive stages; the first one, through the quantitative record of time spent in various activities of everyday life, over a week, enabling the observation of the everyday life organization of the female and male nurses who participated in the study. Differently, the second stage addressed, via interviews, subjective aspects of the experiences of time use. The participants were intentionally included according to the following variables: correct completion of the quantitative data collection instrument - activities booklet; accumulation of more than one working link; occupation of management positions; presence of young children or elderly in the family; as well as completion of graduate school. Those with just one labor link, who did not fill in the booklet of activities in the agreed period, did not live with partners, without children or elderly people at home, and not attending grad school were excluded. After the criteria established, 42 nurses - female and male - participated in all stages of the study.

The fulfillment of the quantitative step was based on records of activities over a sequence of days, including evening periods and weekends. These records were obtained and registered in a booklet of activities prepared by the author, composed by sheets with timetables equivalent to seven days, in which the nurses informed the time devoted to the activities during the week. Red dashes indicate the start and end for the breaks in hours and also every 15 minutes, averaging out 24 hours of the day. To make results closest to the reality expressed by the nurses, when they occupy time day by day, the possibility of registration of activities performed at the same time was ensured. These situations were called throughout the study as "concurrent activities".

It is necessary to point out that the booklet of activities has been developed from the daily use of time diaries, a specific instrument to Time-Use research, whose end is to protocol activities and time for subsequent encoding(6.12). In Brazil, a pioneer research held in Belo Horizonte (MG)(6), revealed the organization of a codebook based on the International Classification of Activities for Time-Use Statistics (ICATUS). This encoding was instrumental in directing the classification of activities that were included in the booklet (paid work, leisure activities, studies, self-care, care of other household activities, transportation, sleep and rest).

The first contact with each nurse was done during workday, looking into the possibility of participation and endorsement. The objectives of the research and the book were presented, and so the walk-through for the record of the time was informed. For the training, the researcher filled in for each professional information on the activities carried out in the previous day, clarifying possible doubts. In the case of acceptance, an informed consent was signed. Only then the booklet was made available for each interviewee, to be completed over seven days. At this point, the date was scheduled to return for a second date (qualitative research step). The purpose was to ensure dates close to the end of records, and so take the completed instrument to quantify the time for each category, prepare a visual scheme that was entitled as map of timetables and conduct a reminding interview to confront the compiled data, from the temporal distribution of the activities recorded in the booklet. Regarding the qualitative step, interviews were held in reserved places, at a previously agreed time with each participant. In the beginning, it was verified lack of information and possible misconceptions on the booklet fill in. To promote dialogue, a road map with open-ended questions related to information produced by their own people during registration of time uses was adopted. Included in this road map were issues related to events and experiments conducted on a daily basis or shared with family, as well as situations that occurred during the time of paid work, provoking dialogues that integrate the two dimensions. Topics such as the following were discussed: organization of time itself; concerns and conflicts related to the domestic sphere and the professional work; division of domestic work; relationship between time used for themselves and for others; and concurrent activities.

Based on the confrontation with the map of timetables, interviews were held in the computer itself, seeking to promote simple self-confrontation. 
This discursive activity, understood as an active and inter-related process allows self-reflections. From studies on the work activity context, the term selfconfrontation aims to promote an inner dialogue in the participant, who during the interview would have difficulty to feel comfortable without the presence of a text (scheme) viewable in the form of image or speech(19).

In this sense, we sought to make this interweaving of techniques a moment for reflection on different temporalities and possible contradictory expressions of everyday relations. That is, to identify gender inequalities, conflicts from the performance of concurrent actions, strains in the relationship between public and private life, in addition to health and illness conditions of the worker.

The quantitative data treatment occurred by comparisons between the time spent on activities by gender, through the Mann-Whitney test, adopting the significance level of $5 \%$. It is worth mentioning that the comparisons were carried out to provide an initial data exploration, considering the limitations of statistical analysis due to the small sample used.

For the analysis of interviews, a thematic analysis technique was chosen, as one of the ways to obtain information expressing in a more reliable manner what the analyzed group(s) thinks about a particular topic (20).

The narratives were analyzed based on dialogues between multiple theoretical references - in this study identified by categories -, such as conflicts of interest, power struggles ${ }^{(1-2)}$, sexual work division ${ }^{(3)}$ and multitasking - polychronic and monochronic concepts $^{(4-5)}$.

The study was approved by the Ethics Committee of the Faculty of Medicine/University Hospital Antônio Pedro/Fluminense Federal University (opinion no. 249/2011) and National School of Public Health/ Fiocruz (opinion no. 205/2011). To respect all ethical precepts of research with humans, we guaranteed confidentiality of those interviewed, identifying testimonials with numbers after the word nurse, at the end of each line.

\section{Results}

The record of time dedicated to activity groups (Table 1) - presented by gender, $57.1 \%$ female nurses and $42.9 \%$ male nurses - made possible the observation of significant differences in relation to paid work, housework, care of others and of themselves.

Table 1- Average time dedicated to groups of gender activities and results of statistical comparisons. Rio de Janeiro, Brazil, 2012

\begin{tabular}{|c|c|c|c|}
\hline \multirow{2}{*}{$\begin{array}{l}\text { Activity } \\
\text { groups }\end{array}$} & \multicolumn{2}{|c|}{ Average time (h:min) } & \multirow{2}{*}{$\begin{array}{c}\text { Result of } \\
\text { statistical test } \\
\text { (Mann-Whitney) }\end{array}$} \\
\hline & $\begin{array}{l}\text { Male nurses } \\
(\mathrm{N}=18)\end{array}$ & $\begin{array}{l}\text { Female nurses } \\
(\mathrm{N}=24)\end{array}$ & \\
\hline Paid work & $52: 26$ & $39: 42$ & $\mathrm{DS}^{*}$ \\
\hline $\begin{array}{l}\text { Domestic } \\
\text { activities }\end{array}$ & 8:03 & $16: 24$ & $\mathrm{DS}^{*}$ \\
\hline Care of others & $7: 58$ & $16: 23$ & $\mathrm{DS}^{*}$ \\
\hline Self-care & $15: 01$ & $18: 52$ & $\mathrm{DS}^{*}$ \\
\hline Sleep/rest & $48: 50$ & $54: 04$ & $\mathrm{NS}^{+}$ \\
\hline $\begin{array}{l}\text { Leisure/social } \\
\text { life }\end{array}$ & $27: 26$ & $25: 03$ & $\mathrm{NS}^{+}$ \\
\hline Studies & 06:08 & 03:06 & $\mathrm{NS}^{+}$ \\
\hline Transportation & $13: 09$ & $12: 14$ & $\mathrm{NS}^{+}$ \\
\hline
\end{tabular}

$*$ DS $=$ significant difference $(p<0.05)$

tNS $=$ non-significant $(p>0.05)$

The data were also grouped together considering categorizations that propose classification based on amount of time hired, indicated by the sum of time spent on paid work and studies; engaged time, designated by the sum of time of housework and care of others; personal time, calculated by the sum of the time occupied with self-care and sleep; and free time, like the one presented through the calculation of activity hours that were not included in the previous items, i.e., it can refer to activities related to social life and transportation ${ }^{(15)}$.

Picturing time uses, from the categorization of activities grouped together in blocks (Table 2) also allowed comparisons by gender.

The record regarding simultaneous time (Table 3), which reflects activities carried out by superposition, when considering the total time spent with the respective activities, was another way to observe gender comparisons, especially when associated with binding, according to the averages of time hired and time engaged. 
An excessive time of professional work, inferring centrality of work in life and overlapping actions linked to family life, raising the performance of concurrent actions, has been found to appear as a common factor in the speech of most participants, showing uncomfortable feelings and concern about their routine. This issue can be observed when a male nurse says that the result came to me a little scary... How dull becomes our day to day routine... You actually do a lot things automatically... (nurse 17); or with the example of a female nurse who, looking at the map of timetables, comments: I didn't know it was that bad, I didn't know it was that serious [...] the real thing... (nurse 61).

Even if the confrontation, from the records of time, makes it possible to identify concerns in the speeches of female and male nurses, it can be observed that most of the female nurses interviewed, when discussed concurrent activities, expressed acceptance naturalized for women. This issue can be exemplified when one observes a report pointing out that it's a question of personality... I love to be able to do several things at the same time ... There comes a time when I'm at my limit, but I have to do it... (nurse 53); or a reference that one has a pretty crazy life [...] all at the same time $[. .$.$] but I can handle it... maybe even by practicing that daily$ $[\ldots]$ it is sometimes stressful, but I'm fine... (nurse 08).

Differently, most men state they try to avoid simultaneous activities in their everyday lives, considering as an example the categorical affirmative of a male nurse who never does several things at the same time $[. .$.$] I think it's terrible ... I think it's a pathological attitude$ ... I organize my time so I can give exclusive attention to what I'm focusing on... (nurse 68).

Putting at the forefront situations related to gender inequalities, based on concurrent activities carried out within the work scope, it is possible to observe the presence of conflicts and inequalities in power relations, which stressed daily. These conflicts appear in the interview of a nurse, when commenting that they hinder the couple's harmony... then, sometimes we're not in the same boat... it gets a little complicated. (nurse 61); and also another participant who says it's my fault, too [...] it comes to a point when I'm tired, but I think he (husband) is more than I am... He takes care of my kids playing the acoustic guitar, his hobby $[. .$.$] surfs on the Internet... I don't have time... and that$ becomes part of my daily life as normal. (nurse 05).

Table 2 - Average of times grouped together into blocks by group studied, and results of statistical comparisons. Rio de Janeiro, Brazil, 2012

\begin{tabular}{|c|c|c|c|}
\hline \multirow[b]{2}{*}{ Classification } & \multicolumn{2}{|c|}{ Average time (h:min) } & \multirow{2}{*}{$\begin{array}{l}\text { Result of statistical test } \\
\text { (Mann-Whitney) }\end{array}$} \\
\hline & $\begin{array}{c}\text { Male nurses } \\
(\mathrm{N}=18)\end{array}$ & $\begin{array}{c}\text { Female nurses } \\
(\mathrm{N}=24)\end{array}$ & \\
\hline Time hired - professional job + studies & $56: 54$ & $42: 07$ & $\mathrm{DS}^{*}$ \\
\hline Time engaged - housework + care of others & 16:01 & $32: 47$ & $\mathrm{DS}^{*}$ \\
\hline Personal time - self-care + sleep & $63: 51$ & $72: 16$ & $\mathrm{DS}^{*}$ \\
\hline Free time - transportation + leisure & 40:00 & $37: 12$ & $\mathrm{NS}^{\dagger}$ \\
\hline
\end{tabular}

* DS = significant difference $(p<0.05)$

+ NS $=$ non-significant $(p>0.05)$

Table 3 - Average time (hours: minutes) spent in concurrent activities, over a week, according to its linkage with time hired or engaged and results of statistical comparisons by gender. Rio de Janeiro, Brazil, 2012

\begin{tabular}{|c|c|c|c|}
\hline \multirow{2}{*}{ Time } & \multicolumn{2}{|c|}{ Average time (h:min) } & \multirow{2}{*}{$\begin{array}{l}\text { Result of statistical test } \\
\text { (Mann-Whitney) }\end{array}$} \\
\hline & $\begin{array}{l}\text { Male nurses } \\
\quad(n=18)\end{array}$ & $\begin{array}{l}\text { Female nurses } \\
\qquad(n=24)\end{array}$ & \\
\hline Total time of concurrent activities & $7: 82$ & $16: 31$ & $\mathrm{DS}^{*}$ \\
\hline Concurrent activities during time hired & $4: 26$ & $4: 19$ & $\mathrm{NS}^{+}$ \\
\hline Time of concurrent activities during time hired & $3: 20$ & $10: 12$ & $\mathrm{DS}^{*}$ \\
\hline
\end{tabular}

*DS $=$ significant difference $(p<0.05)$

+NS $=$ non-significant $(p>0.05)$ 
There are still developments arising from the unequal division of domestic work and its invisibility. When the same worker expresses that sometimes $I$ think I'm going crazy [...] feeling overwhelmed... extremely angry... stressed [...] I have a feeling that I work harder than everyone [...] I'm always tired. (nurse 05). Thus it is possible to say that unequal use of time affects health conditions.

\section{Discussion}

In relation to the average time taken by activity groups (Table 1 ), in addition to the period dedicated to sleep/rest, time dedicated to paid work is the one that most occupies the everyday life of the participants. The results indicate significant difference in relation to the time devoted to paid work: higher among male nurses, with an average of 52 hours, when compared to female nurses, with an average of 39 hours, with a difference of approximately 13 hours. For the time dedicated to domestic activities, the value observed among female nurses in general (16 hours throughout the week) corresponded to twice the observed among male nurses, i.e., an average of 8 hours. In relation to the care of others, the difference is also significant, approximately 9 hours more than female nurses.

Comparisons between men and women on uneven uses of the time occupied with paid work, housework and care of others (children or elderly) can be found in national(7-10) and international studies ${ }^{(16-17)}$.

Directly or indirectly, time spent in the domestic sphere of female nurses is very different than the time of other women with similar educational level and paid work time. An example is the study of executive women, who have high education level (68\% with graduate studies) and claim to spend 45 minutes/ day with housework during weekdays and an average of 103 minutes/day with housework on weekends(8). These data contrast with the time reported by nurses of this research, because even being part of a group with $92 \%$ of graduate professionals (specialization and master's degree), they report that they take up about 700 minutes with housework during the week and an average of 270 minutes with housework on weekends. Thus it is possible to say that female nurses spend much more time in domestic activities, both in comparison with another group of women and with the male nurses of this study.

Moreover, these female nurses also presented significant differences in relation to time spent with selfcare, about 18 hours, when compared to male nurses, whose average is 15 hours. Other activities such as sleep/rest, leisure/social life, studies and transportation did not differ significantly.

For the data analyzed based on the average of the time grouped into blocks by groups studied (Table 2), it can be observed significant differences between female and male nurses regarding times hired, engaged and

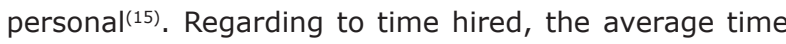
differs by about 14 hours between men and women, with values of 56 and 42 hours per week, respectively. Concerning the time engaged, the difference corresponds to the double, being 16 hours for male nurses and 32 hours for female nurses. For the personal time, the difference drops to approximately 9 hours, statistically significant, which was not observed in the free time.

Thus, one can ratify that male nurses spend more time in the public sphere and female nurses in activities related to the private sphere. Although noting increased female participation in the labor market, men have not proportionally increased their participation in the private life context ${ }^{(9)}$.

In relation to concurrent activities (Table 3), carried out concomitantly among female nurses, the average total time spent over a week was higher than 16 hours, equivalent to more than double the value observed among male nurses (statistically significant, $p=0.011$ ). Male and female group differences also appear in concurrent activities during time engaged $(p=0,013)$, that is, when involved with domestic activities and care of others. However, these same groups do not differ statistically during time hired $(p=0,683)$ Thus, among female nurses, concurrent activities prevail in the private sphere, maybe suggesting that they tend to carry out by superposition both domestic activities and care of others, in an average of 10 hours over a week. Among male nurses, however, concurrent activities 
are more linked to time hired, dropping the difference between time hired and time engaged (around 1 hour), in comparison with female nurses (around 6 hours).

It is worth to highlight that the effort to include the possibility of record of concurrent situations in the booklet of activities was a challenge, in view of notes regarding the difficulties faced by researchers when analyzing time uses to gather accurate and complete data, against everyday dynamism of human activity. However, the significant response of the nurses was very significant, since it permitted a way of identifying unequal time uses between genders.

In this way, based on the models of one-to-one mentoring or Western organization of time, considering polychronic-monochronic concepts ${ }^{(4-5)}$, it was possible to identify the types of time that prevail in the daily lives of female and male nurses. From the record of concurrent activities, the differences that emerged by group allowed to reveal gender inequalities. Overall, male nurses' records allowed the identification of an organization that is close to the monochronic approach, that is, the one characterized by a linear time, sequential, disciplined, controlled and marked by actions that are performed separately. And the group of female nurses was tendentiously associated with a polychronic organization, represented by multiple events at the same time, with a higher possibility of breaking schedules and the traditional female view in relation to the accumulation of roles in private life.

Through self-confrontation, performed during the interviews, it can be observed that the experiences recorded in the maps of timetables - which feature restricted time uses through overlapping actions ${ }^{(9)}$ - are also more present in the speeches of female nurses. It is worth noting that female nurses in general hinted at the need for more concurrent actions in a limited period, with emphasis on the existing overlaps in time engaged in the domestic sphere. This trend seems so naturalized in most female lines, even if the presence of conflicts of interests and tensions is highlighted, based on the Theory of Interdependence Configurations ${ }^{(1-2)}$.

However, it is observed that simultaneous experiences somehow affected dependency relationships, both in the lives of female and male nurses, causing, in many situations, stresses and weariness. To record the time and confront it - in a relationship of contradictions between excess and lack of time - has raised the possibility of situations of fright, exhaustion and sadness, associated to stress. So, one can say that relations of interdependency in the way of how time is organized permits the identification of conflicts, tensions and power struggles ${ }^{(1-2)}$, which - for this group of professionals - not only characterize inequalities related to the sexual work division ${ }^{(3)}$, but also physical and mental health conditions affected ${ }^{(7)}$.

The confrontation performed by the participant, through the image of the timetables map used during the interviews about the time cataloged in booklets over the course of a week, seems to promote, in some cases, opportunity for reflections on the development of their own daily lives. A differentiated perspective about their relationships with themselves and with other people on a daily basis enabled diverse reactions, translating it into an opportunity to look at life and make a selfanalysis and to think about health issues. In this way, the disproportion between available time for him/herself and for others - taking into account the implementation of concurrent activities and centrality of the paid work in life -, causes, in addition to cumulative exhaustion that affects emotional and physical health, power struggles and conflicts, which enhance tension in gender relations.

In relation to the contribution of this study, it is worth pointing out some limitations such as: resistance to participation - fear of exposing their private life; difficulty of endorsement of participants, since it was a seven-day commitment; reminding attitude for the record in the booklet, presenting risk of underestimating the accuracy of time due to the daily life dynamism; and absence of aspects related to the context and to the people who shared the researched time.

\section{Conclusion}

The thematic investigated analysis derived from a relational approach and allowed reflections on the borders between the spaces and times of nurses' daily life. On the one hand, one can observe the presence of trends that point out changes in the traditional relations 
between genders, both in private and public life. But on the other hand, there are many obstacles hampering the process of change of these positions naturalized by biological aspects and historical and cultural factors. In general, the daily life of these professionals, from the time in the hospital, has been permeated by conflicts of interests and power struggles, making it possible to reveal differences related to housework and concurrent activities, use of time to him/herself and others and the way the interviewees notice health and tensions arising from the unequal relations as well as unequal uses of time. Nevertheless, when it comes to a busy life, overlapping actions and overload in paid and unpaid work, it is clear for both groups a strained relationship between times, whose rebound affects gender relations, health conditions and ways of life.

Concerning health/disease process, both groups seem affected by these forms of relationship with time. Female nurses express higher levels of weariness, through experiences that highlight the presence of fatigue and overload related to days of uninterrupted work and limited uses of time, featuring greater use of time committed to others than for themselves. Male nurses, although reporting concurrent experiences, tend to preserve a little more time for themselves. And even claiming more time spent with paid work, they seek to avoid or even to control the overlapping uses of time.

Thus, the results pointed out the need of public policies that promote equity in gender relations, keeping at sight more tolerant attitudes and plural discourses that respect the differences between individual and collective time.

\section{Acknowledgments}

To PhD professors Lucia Rotenberg, from Instituto Oswaldo Cruz/Fundação Oswaldo Cruz and Simone Santos Oliveira, from Escola Nacional de Saúde Pública/ Fundação Oswaldo Cruz, for the important reflections and shared guidance during the preparation of the doctoral thesis.

To the female and male nurses who anonymously participate in this research.

\section{References}

1. Hunger D, Rossi F, Neto SS. A teoria de Norbert Elias: uma análise do ser professor. Educ Pesqui. 2011;37(4):697-710.

2. Pereira AV, Rotenberg L, Oliveira SS. Relações de Gênero e Interdependências: reflexões a partir de mudanças na configuração hospitalar. História, Ciências, Saúde - Manguinhos. 2013;20(3):1007-24.

3. Hirata H, Kergoat D. Novas configurações da divisão sexual do trabalho. Cad Pesqui. 2007;37(132):595-609.

4. Lindquist JD, Kaufman-Scarborough CF. Polychronic tendency analysis: a new approach to understanding women's shopping behaviors. J Consumer Market. [Internet]. 2004 [acesso15 nov 2013];21(5):332-42. Disponível em: http://www.emeraldinsight.com/doi/ pdfplus/10.1108/07363760410549159. ISSN 07363761 DOI 10.1108/07363760410549159

5. Bluerdorn AC, Kaufman CF, Lane PM. How many things do you like to do at once? An introduction to monochronic and polychronic time. Acad Manage Exec. 1992;6(4):17-26.

6. Aguiar NF. Metodologias para o levantamento do uso do tempo na vida cotidiana no Brasil. Rev Econômica. 2010;12(1):64-82.

7. Rotenberg L. Relações de gênero e gestão dos tempos - a articulação entre o trabalho profissional e doméstico em equipes de enfermagem no Brasil. Laboreal. 2012;8(1):72-84.

8. Cyrino R. A gestão do trabalho doméstico entre mulheres executivas: um exemplo de combinação de dados de uma pesquisa de Usos do Tempo com metodologia qualitativa. Política e Trabalho. 2011;34:145-62.

9. Dedecca CS, Ribeiro CSMF, Ishii FH. Gênero e jornada de trabalho: análise das relações entre mercado de trabalho e família. Trab Educ Saúde. 2009;7(1):65-90.

10. Ramos DP. Pesquisas de usos do tempo: um instrumento para aferir as desigualdades de gênero. Estud Feministas. 2009;17(3):861-70.

11. Chenu A, Lesnard L. Time Use Surveys: a Review of their Aims, Methods, and Results. Eur J Sociol. 2006;47(3):335-59.

12. Harvey A, Spinney J. Activity and contextual codes Implications for time-use coding schemes. eIJTUR. 
[Internet]. 2011 [18 dez 2013]; 8(1):110-35. Disponível em: http://www.eijtur.org/pdf/volumes/eIJTUR-8-1.pdf. dx.doi.org/10.13085/eIJTUR.8.1.110-135.

13. Österbacka E, Merz J, Zick CD. Human capital investments in children - A comparative analysis of the role of parent-child shared time in selected countries. eIJTUR. [Internet]. 2012 [18 dez 2013]; 9(1):120-43. Disponível em: http://www.eijtur.org/pdf/volumes/ eIJTUR-9-1.pdf. dx.doi.org/10.13085/eIJTUR.9.1. 120-143

14. Robinson JP, Gershuny J. Visualizing multinational daily life via multidimensional scaling (MDS). eIJTUR. [Internet]. 2013 [18 dez 2013]; 10(1):76-90. Disponível em: http://www.eijtur.org/pdf/volumes/eIJTUR-10-1-2_ Chapela.pdf dx.doi.org/10.13085/eIJTUR.10.1.76-90

15. Stinson LL. Measuring how people spend their time: a time-use survey design. Monthly Labor Rev. $1999 ; 122(8): 12-9$.

16. Deding $M$, Lausten $M$. Choosing between his time and her time? Paid and unpaid work of Danish couples. eIJTUR. [Internet]. 2006 [19 dez 2013]; 3(1):2848. Disponível em: http://ffb.uni-lueneburg.de/eijtur/ pdf/volumes/eIJTUR-3-1.pdf\#page=29. dx.doi. org/10.13085/eIJTUR.3.1.28-48

17. Fisher K, Layte R. Measuring Work-Life Balance Using Time Diary Data. eIJTUR. [Internet]. 2004 [19 dez 2013]; 1(1):1-13. Disponível em: http:// ffb.uni-lueneburg.de/eijtur/pdf/volumes/eIJTUR-1-1. pdf\#page=8. dx.doi.org/10.13085/eIJTUR.1.1.1-13

18. Schulz F, Grunow D. Comparing Diary and Survey Estimates on Time Use. Eur Soc Rev. 2012;28(5):622-32. 19. Faïta $D$, Vieira $M$. Réflexions méthodologiques sur I'autoconfrontation croisée. D.E.L.T.A. 2003;19(1):123-54.

20. Câmara RH. Análise de Conteúdo: da teoria à prática em pesquisas sociais aplicadas às organizações. Gerais:

Rev Interinstitucional Psicol. 2013;6(2):179-91. 